\title{
GENETIC STUDIES OF A CYTOPLASMIC SUPPRESSOR WHICH INACTIVATES THE MALE RECOMBINATION FACTOR 31.1 MRF IN DROSOPHILA MELANOGASTER
}

\author{
GEORGE YANNOPOULOS, NIKOS STAMATIS and ANTIGONE ZACHAROPOULOU \\ Department of Genetics, University of Patras, Patras, Greece \\ Received 24.iii.82
}

\section{SUMMARY}

The cytoplasm of a laboratory strain $C y L^{4} / P m$ was found to suppress the activities of the $31.1 \mathrm{MRF}$ but not those of the $23.5 \mathrm{MRF}$. However, this strain induces neither male recombination nor sterility which are the main properties of the MRFs. By measuring, in successive generations, the female sterility in two series of established strains (one received the cytoplasm of the $C y L^{4} / P m$ strain and the other of the M-5; $d p ; U b x / S b)$ when crossed with $31 \cdot 1 / C y L^{4}$ males, we have been able to show that: (a) the suppressor factor is controlled by the nucleus and the $C y L^{4}$ or $P m$ chromosomes are mainly responsible for its development; (b) the chromosome III of the $C y L^{4} / P m$ strain induces either lower quantities of the suppressor or an altered substance incapable of completely suppressing the $31.1 \mathrm{MRF}$ and (c) the cytoplasmic suppressor of the Cy $L^{4} / P m$ strain may be responsible for the stimulation of pre-existing genes which are located on the $U b x$ or $S b$ chromosomes and are capable of synthesizing the suppressing substance(s). By using the $23.5 \mathrm{MRF}$ it was shown that the suppressor activity developed by the established strains is identical with that of the $C y L^{4} / P m$ strain.

The existence of a possible relationship in the nature of both, 31.1 MRF genetic elements and the genetic factors responsible for the development of the suppressor in the $C y L^{4} / P m$ strain, as well as the role of the suppressors in the maintenance of the MRFs in natural populaţions, are also discussed.

\section{INTRODUCTION}

A LABORATORY strain of Drosophila melanogaster, the $C y L^{4} / P m$, which was used to isolate the 31.1 male recombination factor (MRF), wild chromosome II, was found to suppress the activities of the $31 \cdot 1 \mathrm{MRF}$. However, this strain induces neither male recombination nor sterility which are the main properties of the MRFs (Yannopoulos, 1978c; Yannopoulos, 1979). The suppressor factor possessed by the $C y L^{4} / P m$ strain has been shown to be cytoplasmic (Yannopoulos and Pelecanos, 1977). The cytoplasm of the $C y L^{4} / \mathrm{Pm}$ strain, while suppressing $31 \cdot 1 \mathrm{MRF}$ does not affect the activities of another factor, $23.5 \mathrm{MRF}$, which was also isolated from the same natural population (Stamatis et al., 1981).

All strains bearing male recombination factors isolated until now from natural populations of Drosophila melanogaster show the reciprocal cross effect, that is, they are active only when inherited from the males of the MRF strains. This has been shown to be due either to a cytoplasmic suppressor (Yannopoulos and Pelecanos, 1977; Yannopoulos, 1978a, b; Kidwell, 1978) or to the X chromosome of the MRF strain (Slatko and Hiraizumi, 1978).

When $31.1 \mathrm{MRF}$, is introduced by outcrossing into the cytoplasm of a laboratory strain by which it is not suppressed, the new strain progressively 
acquires a cytoplasmic resistance against the activities of the factor (Yannopoulos, 1978b). This indicates that the chromosomes bearing the 31.1 MRF are responsible for the induction of the cytoplasmic resistance in the new strain.

The present investigation was undertaken in order to assess whether the cytoplasmic suppressor possessed by the $C y L^{4} / P m$ strain is controlled by the nucleus or the cytoplasm.

\section{MATERIALS AND METHODS}

The following strains of Drosophila melanogaster, maintained at $25^{\circ} \mathrm{C}$, were used. (For a description of mutants and balanced strains, see Lindsley and Grell, 1968.)

(a) $d p b c n b w ;$ ve $(2-13 \cdot 0,2-48 \cdot 5,2-57 \cdot 5,2-104 \cdot 5,3-0 \cdot 2)$.

(b) A balanced strain $C y L^{4} / P m=\operatorname{In}(2 \mathrm{~L}+2 \mathrm{R}) C y, C y, L^{4}, s p^{2}$ bearing also the cytoplasmic suppressor of the activities of the $31 \cdot 1 \mathrm{MRF}$.

(c) A balanced strain for the 1st and 3rd chromosome M-5; dp b cn bw; $U b x^{130} / S b=\left|\operatorname{In}(1) s c^{\text {S1L }} s c^{8 R} ; 2 ; \operatorname{In}(2 \mathrm{LR}) U b x^{130}, U b x^{130} e^{s}\right|$ designated below as M-5; $d p ; U b x / S b$. This strain, established by us 8 years ago, gives high frequencies of sterile females when crossed with $31 \cdot 1 / \mathrm{Cy}^{4}$ males at both $25^{\circ} \mathrm{C}$ and $28^{\circ} \mathrm{C}$ (Stamatis, et al., 1981).

(d) $31 \cdot 1 / C y L^{4}$, a wild second chromosome line bearing the $31 \cdot 1 \mathrm{MRF}$ elements* in both the second and third chromosomes (Yannopoulos, $1978 \mathrm{a} ; 1979)$.

(e) $23 \cdot 5 / C y L^{4}$, a wild chromosome line bearing the $23.5 \mathrm{MRF}$ elements* (Stamatis, et al., 1981).

A standard cornmeal food was used throughout the present experiments. Parents were 2-3 days old when crossed. In the male recombination tests, progeny were scored until the 17 th day after the parents had been mated. The cultures were kept in $25^{\circ} \mathrm{C}$ or $28^{\circ} \mathrm{C}$ incubators, according to the experiments (see results).

The process of the collection of female progeny and the examination of their ovaries is described elsewhere (Yannopoulos, 1978c). Female sterility is characterized by the atrophy of both ovaries. For estimating female sterility, more than 200 progeny were dissected from each cross.

\section{RESUlts}

Two series of strains A and B were established by means of the crosses given in figure 1 . The A strains have the cytoplasm of the $\mathrm{M}-5 ; d p ; U b x / S b$ strain while B that of the $C y L^{4} / P m$. Both series A and B carry different combinations of chromosome pairs from the $C y L^{4} / P m$ strain. These series were constructed in order to test whether the cytoplasmic suppressor of the $C y L^{4} / P m$ is controlled by the nucleus or by the cytoplasm.

The M-5; $d p ; U b x / S b$ virgin females provide high frequencies of female sterility (95-100 per cent), while $C y L^{4} / P m$ very low (0-3 per cent), whenever crossed with $31 \cdot 1 / C y L^{4}$ males, at $28^{\circ} \mathrm{C}$ (Stamatis, et al., 1981;

\footnotetext{
* Whenever in the text we refer to $31.1 \mathrm{MRF}$ and 23.5 MRF we mean chromosomes bearing the corresponding MRF elements.
} 
A

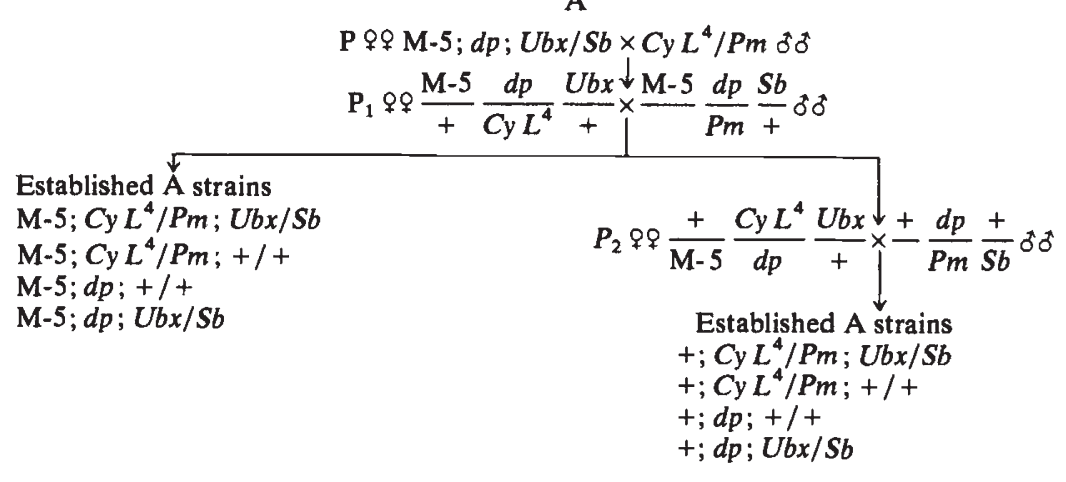

B

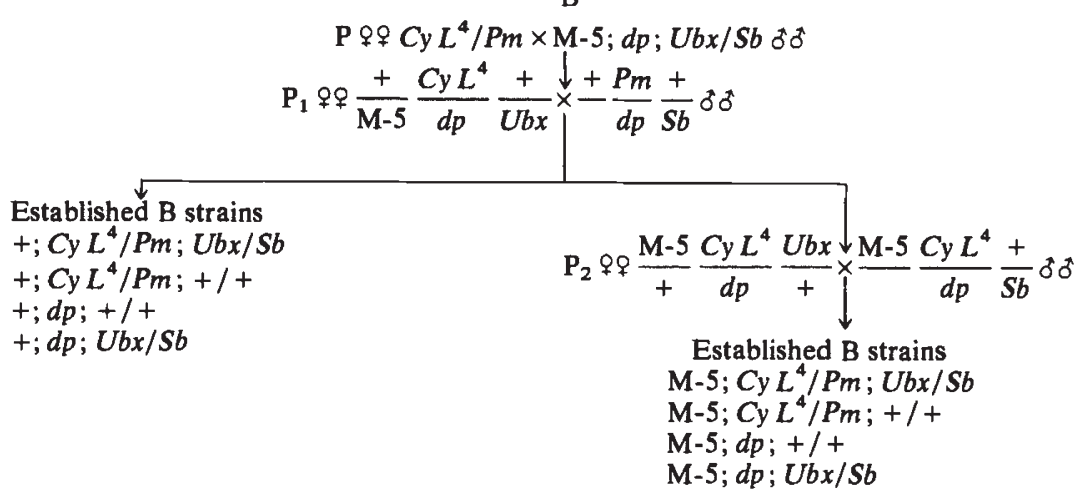

FIG. 1.-Crosses performed for the establishment of the A and B strains.

and unpublished data). $\mathrm{AF}_{1}$ and $\mathrm{BF}_{1} \mathrm{M}-5 /+; C y L^{4} / d p ; U b x /+$ virgin females derived from the corresponding $A$ and $B$ crosses (fig. 1), were crossed separately with $31 \cdot 1 / C y L^{4}$ males at $28^{\circ} \mathrm{C}$. Their female progenies have shown 94 and 4 per cent sterility respectively. This implies that the cytoplasm of the $C y L^{4} / P m$ stock is responsible for the suppression of the $31 \cdot 1$ MRF. From each of the above crosses as well as from these described below we examined separately all possible genotypes heterozygous for the 31.1 chromosome II females. As no difference in the number of sterile females was found among the various genotypes, the results were pooled.

In order to examine whether the various $A$ strains developed the suppressor factor and the B strains "retained" it in successive generations, we measured the female sterility up to the 20 th generation $(G)$ after their establishment. In doing so we crossed virgin females from the $A$ and $B$ strains with $31 \cdot 1 / C y L^{4}$ males at $28^{\circ} \mathrm{C}$ and examined their daughters. At this temperature the $31 \cdot 1 \mathrm{MRF}$ usually expresses itself (Stamatis et al., 1981).

The frequencies of the sterile daughters yielded by the $\mathrm{A}$ and $\mathrm{B}$ strains in successive generations (G1-G20) are presented in table 1 sections $A$ and B, respectively. The A strains that developed complete suppressor activities in a relatively short time were those bearing the following chromosomes 
TABLE 1

Percentage of female sterility yielded by the $A$ and $B$ strains when crossed with $31 \cdot 1 / \mathrm{Cy} \mathrm{L}^{4}$ males

\begin{tabular}{|c|c|c|c|c|c|c|}
\hline A strains & $\mathbf{G} 1 \dagger$ & G3 & G6 & G14 & G16 & G20 \\
\hline 1. M-5;Cy $L^{4} / P m ; U b x / S b$ & 20 & 3 & 0.68 & 0 & 0 & 0 \\
\hline 2. $\mathrm{M}-5 ; C y L^{4} / P m ;+/+$ & 18 & 2 & $1 \cdot 39$ & 4 & 0 & 0 \\
\hline 3. $\mathrm{M}-5 ; d p^{*} ;+/+$ & 79 & 35 & 43 & 44 & 42 & 45 \\
\hline 4. $\mathrm{M}-5 ; d p ; U b x / S b$ & 93 & 91 & 97 & 100 & 100 & 100 \\
\hline 5. $+/+; C y L^{4} / P m ; U b x / S b$ & 38 & 3 & 2 & 4 & 2 & 3 \\
\hline 6. $+/+; C y L^{4} / P m ;+/+$ & 48 & 43 & 0.35 & 0.34 & 1 & 0.25 \\
\hline 7. $+/+; d p ;+/+$ & 39 & 35 & 30 & 22 & 17 & 3 \\
\hline 8. $+/+; d p ; U b x / S b$ & 78 & 80 & 95 & 100 & 100 & 100 \\
\hline 1. M-5;Cy $\begin{array}{l}\text { B strains } \\
L^{4} / P m ; U b x / S b\end{array}$ & 0 & 2 & 0.5 & 0 & 0 & 0 \\
\hline 2. M-5;Cy $L^{4} / P m ;+1+$ & 0 & 3 & 6 & 6 & 3 & 4 \\
\hline 3. $\mathrm{M}-5 ; d p ;+/+$ & 55 & 44 & 42 & 49 & 41 & 42 \\
\hline 4. M- $5 ; d p ; U b x / S b$ & 10 & 3 & 2 & 1 & 2 & 2 \\
\hline$+/+; C y L^{4} / P m ; U b x / S b$ & 15 & 3 & 0 & 2 & 0 & 0 \\
\hline 6. $+/+; C y L^{4} / P m ;+/+$ & 0 & 5 & 1 & 1 & 0 & 0 \\
\hline$+/+; d p ;+1+$ & 25 & 30 & 17 & 16 & 8 & 0 \\
\hline$+/+; d p ; U b x / S b$ & 7 & 9 & 3 & 5 & 3 & 2 \\
\hline
\end{tabular}

* $d p$ : stands for the whole $d p b c n b w$ chromosome.

† G: Generation.

from the $C y L^{4} / P m$ strain: II (line 1), II-III (line 2), I-II (line 5), I-II-III (line 6); that is only those carrying the $C y L^{4}$ and $P m$ chromosomes. Where chromosomes I and III were present, the complete acquisition of the suppressor took more than 16 generations (line 7). Finally, the strain carrying chromosome III developed almost half suppressor activities (line 3), while those having the I or no chromosome from the $\mathrm{Cy} \mathrm{L}^{4} / \mathrm{Pm}$ strain, did not exhibit any suppressor activities (lines 8 and 4, respectively).

With the B strains the results were different. Complete suppressor activities were exhibited not only by strains bearing the $C y L^{4}$ and $P m$ chromosomes (lines 1, 2, 5 and 6) but also by those bearing the $U b x$ and $S b$ chromosomes (lines 4 and 8 ). The strains having chromosome III (line 3 ) and I-III (line 7) behaved in a similar way to the corresponding A strains.

In order to assess whether the complete suppressor activity of the $A$ and $\mathrm{B}$ strains was also cytoplasmic we crossed $\mathrm{A}+/+; \mathrm{Cy} \mathrm{L}^{4} / \mathrm{Pm} ;+/+$ males derived from $\mathrm{G} 20$ with virgin females from the original $\mathrm{M}-5$; $d p$; $U b x / S b$ strain at $25^{\circ} \mathrm{C}$. Daughters of the genotype $\mathrm{M}-5 /+; C y L^{4} / d p$; $U b x /+$ were then mated with $31 \cdot 1 / C y L^{4}$ males at $28^{\circ} \mathrm{C}$ and their progeny was examined for sterility. The sterility found was 97 per cent, showing that the suppressor factor of the $\mathrm{A}+/+; C y L^{4} / P m$; $+/+$ strain is cytoplasmic as in the original $C y L^{4} / P m$ strain.

On the contrary the cytoplasmic suppressor possessed by the $C y L^{4} / P m$ strain does not affect the 23.5 MRF (Stamiatis et al., 1981). In order to detect whether the suppressor factor acquired by the A M-5; $C y L^{4} / P m$; $U b x / S b$ and $+/+; C y L^{4} / P m ;+/+$ strains as well as that "retained" by the B M-5; $d p ; U b x / S b$ and $+/+; C y L^{4} / P m ;+/+$ strains is identical with that of the $C y L^{4} / P m$ strain, we crossed virgin females from these strains derived from $\mathrm{G} 20$ with $23 \cdot 5 / \mathrm{Cy} \mathrm{L}^{4}$ males at $25^{\circ} \mathrm{C}$. At this temperature the $23.5 \mathrm{MRF}$ usually expresses itself (Stamatis, et al., 1981). The frequencies of the sterile daughters heterozygous for the 23.5 chromosome 


\section{TABLE 2}

Female sterility yielded by $A, B$ and the original $\mathrm{Cy}^{4} \mathrm{~L}^{4} / \mathrm{Pm}$ strains when mated with $23 \cdot 5 / \mathrm{Cy} \mathrm{L}^{4}$ males

\begin{tabular}{|c|c|c|}
\hline & $\begin{array}{l}\text { Female } \\
\text { sterility } \\
\text { per cent }\end{array}$ \\
\hline $\begin{array}{l}\text { G20 } \\
\text { G20 }\end{array}$ & $\begin{array}{c}\text { M-5;Cy } L^{4} / P m ; U b x / S b \\
+/+; C y L^{4} / P m ;+/+\end{array}$ & $\begin{array}{l}54 \\
52\end{array}$ \\
\hline & B strains & \\
\hline $\begin{array}{ll}\text { 1. } & \mathbf{G 2 0} \\
2 . & \mathbf{G 2 0}\end{array}$ & $\begin{aligned} \text { M-5: } d p^{*} ; U b x / S b \\
+/+; C y L^{4} / P m ;+/+ \\
\text { Cy } L^{4} / P m\end{aligned}$ & $\begin{array}{l}61 \\
57 \\
52\end{array}$ \\
\hline
\end{tabular}

II, which are presented in table 2, show that the suppressor acquired by $\mathrm{A}$ and retained by B strains is identical with that of the original $C y L^{4} / P m$ strain.

The A M-5; $d p ; U b x / S b, \mathrm{M}-5 ; d p ;+/+$ and the B M-5; $d p ; U b x / S b$ strains that gave female sterilities of 100,45 and 0 per cent respectively in G20, were tested for male recombination to see whether there is a correlation between female sterility and male recombination. We mass mated virgin females from these strains with $31 \cdot 1 / C y L^{4}$ males at $25^{\circ} \mathrm{C}$. Males heterozygous for the 31.1 chromosome II were then individually mated with $d p b c n b w$; ve virgins and their progeny scored for recombinants. The results presented in table 3 clearly show that female sterility and male recombination are related.

\section{TABLE 3}

Second chromosome male recombination by $31 \cdot 1 \mathrm{MRF}$

$\begin{array}{ccccc}\begin{array}{c}\text { Mating type } \\ \$ \times \delta\end{array} & \begin{array}{c}\text { No. } \\ \text { of } \delta^{\delta} \\ \text { tested }\end{array} & \begin{array}{c}\text { No. of } \\ \text { progeny }\end{array} & \begin{array}{c}\text { Total no. of } \\ \text { recombinants } \\ \text { (per cent) }\end{array} & \begin{array}{c}\delta \delta^{*} \text { which } \\ \text { yielded } \\ \text { recombinants }\end{array} \\ p^{*} \quad U b x / S b \times 31 \cdot 1 / C y L^{4} & 23 & 1572 & 32(2 \cdot 04) & 16 \\ ;+/+\times 31 \cdot 1 / C y L^{4} & 15 & 2775 & 27(0.97) & 7 \\ ; U b x / S b \times 31 \cdot 1 / C y L^{4} & 15 & 2450 & 0 & 0\end{array}$

$\begin{array}{llccc}\text { 1. AM-5; } d p^{*} ; U b x / S b \times 31 \cdot 1 / C y L^{4} & 23 & 1572 & 32(2 \cdot 04) & 16 \\ \text { 2. AM-5; } d p ;+/+\times 31 \cdot 1 / C y L^{4} & 15 & 2775 & 27(0 \cdot 97) & 7 \\ \text { 3. BM-5; } d p ; U b x / S b \times 31 \cdot 1 / C y L^{4} & 15 & 2450 & 0 & 0\end{array}$

* $d p$ : stands for the whole $d p b$ cn $b w$ chromosome.

\section{Discussion}

The data of the present series of experiments suggest that the suppressor factor of the $C y L^{4} / P m$ strain which inactivates the $31 \cdot 1 \mathrm{MRF}$ is controlled by the nucleus. Moreover, the results of table 1 clearly show that the $C y L^{4}$ or $P m$ chromosomes are mainly responsible for the development of the suppressor. The observation that the B M-5; $d p ;+/+$ strain lost almost half of its suppressor activities and behaved similarly with the corresponding A strain after G3, provides evidence that the third chromosome of the Cy $L^{4} / P m$ strain is also responsible for the synthesis either of lower quantities of the suppressor, or an altered substance which does not have the ability to suppress completely the $31 \cdot 1 \mathrm{MRF}$. These results also indicate 
that the complete suppressor activities exhibited by the B strains in successive generations, cannot be due to the quantity of the suppressor received from the original $C y L^{4} / P m$ strain. It is more probable that new suppressor has been synthesized in successive generations. This would be expected since the cytoplasmic substances would be diluted by cell divisions.

The complete suppressor activity shown by the B M-5; $d p ; U b x / S b$ strain, may be attributed to the fact that the cytoplasmic suppressor received from the $C y L^{4} / P m$ strain has stimulated pre-existing genes able to synthesize the suppressor. In consequence this would mean that some cytoplasmic regulation of gene expression exists. The stimulated genes must be located on the $U b x$ or $S b$ chromosome and are not expressed in the original or in the A M-5; $d p ; U b x / S b$ strains. This view is also supported by the finding that the $\mathrm{B}+1+; d p ; U b x / S b$ strain developed the suppressor, while the corresponding A strain did not. Finally, the similar behaviour of the $A$ and $\mathrm{B}+/+; d p ;+/+$ strains provides evidence that the $\mathbf{X}$ and third chromosome of the $C y L^{4} / P m$ strain interacted with each other in the development of the suppressor.

Table 3 shows that both male recombination and sterility induced by 31.1 MRF follow the same pattern. Moreover, A and B strains which developed complete suppressor activities against 31.1 MRF gave similar female sterility as the original $C y L^{4} / P m$ strain, when mated with $23 \cdot 5 / C y L^{4}$ males (table 2). This observation suggests that the cytoplasmic suppressor developed is identical with that of the $C y L^{4} / P m$ strain.

Taking into account: (a) the observation that the cytoplasmic suppressor of the $C y L^{4} / P m$ strain as well as those developed by the A and B strains exhibit their activity only on the $31 \cdot 1 \mathrm{MRF}$ and (b) the finding that 31.1 MRF and 23.5 MRF suppress each other (Stamatis et al., 1981), we may assume that the "cytotypes" (Engels, 1979) of the $C y L^{4} / P m$ and $31 \cdot 1 / C y L^{4}$ strains are not identical. Thus, according to the P-M model proposed by Engels (1979) both, 23.5/Cy $L^{4}$ and 31.1/Cy $L^{4}$ strains belong to the $P$ category and the $C y L^{4} / P m$ strain in relation to $31 \cdot 1 / C y L^{4}$ belongs to the $P$ category, while in relation to the $23 \cdot 5 / C y L^{4}$ strain belongs to the $M$ category.

The different response of the 31.1 and $23.5 \mathrm{MRF}$ to the cytoplasm of the $C y L^{4} / P m$ strain as well as the other specific differences exhibited, were attributed to the fact that they constitute closely related elements or mutants of one original element (for more details see Stamatis et al., 1981; Yannopoulos, et al., 1981).

When 31.1 MRF is introduced by outcrossing into the cytoplasm of a laboratory strain, the new strain acquires progressively a cytoplasmic resistance against the activities of the factor (Yannopoulos, 1978b). Whether there is any relationship between MRF genetic elements and the genetic factor(s) borne by the $C y L^{4} / P m$ strain remains obscure. At any rate, the observation that both, $31 \cdot 1$ and $23.5 \mathrm{MRF}$ developed identical cytotypes (based on the present data, Stamatis, et al., 1981) when introduced by outcrossing into the $C y L^{4} / P m$ background, almost excludes the existence of any relationship between MRF elements and the genetic factors possessed by the $C y L^{4} / P m$ strain. It seems unlikely that the $C y L^{4} / P m$ strain had the properties of the $31 \cdot 1 \mathrm{MRF}$ in the past but has now become free of them, because the same properties have been maintained by the $31 \cdot 1 / C y L^{4}$ strain since 1971. 
The significance of the suppression that is exhibited by the $C y L^{4} / P m$ and MRF strains lies in its role as a cellular defence mechanism against the harmful activities (chromosome breakage, mutations, sterility) of the MRFs. Furthermore, the immigration in natural populations of individuals bearing such factors as those possessed by $C y L^{4} / P m$, would have increased relatively rapidly the defence of the population against the activities of at least some MRFs. Thus, on the basis of the previous finding as well as from the fact that individuals bearing MRF elements possess the ability to develop cytoplasmic resistance against their activities, we can provide a plausible explanation for the high frequencies detected in natural populations (Slatko and Hiraizumi, 1973; Broadwater et al., 1973; Woodruff and Thompson, 1977; Stamatis, 1981).

\section{REFERENCES}

BROADWATER, C,, OWENS, L. V., PARKS, R,, WINFREY, E., AND WADDLE, F. R. 1973. Male recombination from natural populations of Drosophila melanogaster. Drosophila Information Service, 50, 99.

ENGELS, W. R. 1979. Hybrid dysgenesis in Drosophila melanogaster: Rules of inheritance. Genetical Research, 33, 219-236.

KIDWELL, M. G. 1978. Hybrid dysgenesis in Drosophila melanogaster: No suppressor-X effect on male recombination. The Journal of Heredity, 69, 417-419.

LINDSLEY, D. L.. AND GRELL. E. H. 1968. Genetic Variation of Drosophila melanogaster, Carnegie Institute of Washington publication.

SLATKO, B. E., AND HIRAIZUMI, Y. 1973. Mutation induction in the male recombination strain of Drosophila melanogaster. Genetics, 75, 643-649.

SLATKO, B. E., AND HIRAIZUMI, Y. 1978. Genetic suppression of male recombination activity in Drosophila melanogaster. Genetics, 88 (supl.), 92.

STAMATIS, N. 1981. Male recombination elements in a Southern Greek Drosophila melanogaster population. Drosophila Information Service, 56, 129.

STAMATIS, N.. YANNOPOULOS, G., AND PELECANOS, M. 1981. Comparative studies of two male recombination factors (MRF) isolated from a Southern Greek Drosophila melanogaster population. Genetical Research, 38, 125-135.

WOODRUFF, R. C., AND THOMPSON, J. N. JR. 1977. An analysis of spontaneous recombination in Drosophila melanogaster males. Isolation and characterization of male recombination lines. Heredity, 38, 291-307.

YANNOPOULOS, G. 1978a. Studies on male recombination in a Southern Greek Drosophila melanogaster population. (c) Chromosomal abnormalities at male meiosis. (d) Cytoplasmic factor responsible for the reciprocal-cross effect. Genetical Research, 31, 187-196.

YANNOPOULOS, G. 1978 b. Progressive resistance against the male recombination factor 31-1 MRF acquired by Drosophila melanogaster. Experientia, 34, 1000-1002.

YANNOPOULOS, G. 1978c. Studies on the sterility induced by the male recombination factor 31.1 MRF in Drosophila melanogaster. Genetical Research, 32, 239-247.

YANNOPOULOS, G. 1979. Ability of the male recombination factor $31 \cdot 1 \mathrm{MRF}$ to be transposed to another chromosome in Drosophila melanogaster. Molecular and General Genetics, 176, 247-253.

YANNOPOULOS, G., AND PELECANOS, M. 1977. Studies on male recombination in a Southern Greek Drosophila melanogaster population. (a) Effect of temperature. (b) Suppression of male recombination in reciprocal crosses. Genetical Research, 29, 231-238.

YANNOPOULOS, G., STAMATIS, N., ZACHAROPOULOU. A.. AND PELECANOS. M. 1981. Differences in the induction of specific deletions and duplications by two male recombination factors isolated from the same Drosophila natural population. Mutation Research, 83, 389-393. 